\title{
Epstein-Barr virus infection in the pathogenesis of nasopharyngeal carcinoma
}

\author{
G Niedobitek
}

\begin{abstract}
The association of nasopharyngeal carcinoma (NPC) with the Epstein-Barr virus (EBV) was firmly established as early as 1973. Nevertheless, the role for the virus in the pathogenesis of NPC is still controversial. In this article, the evidence implicating EBV in the development of NPC is reviewed, focusing on the cellular site of EBV persistence, the association of the virus with different NPC histotypes, the tumour cell phenotype in the context of viral latent gene expression, and the possible role of the lymphoid stroma. (F Clin Pathol: Mol Pathol 2000;53:248-254)
\end{abstract}

Keywords: Epstein-Barr virus; nasopharyngeal carcinoma; viral latent gene expression

The past 15 years have witnessed a great expansion of the spectrum of tumours known to be associated with Epstein-Barr virus (EBV) infection. In addition to the familiar Burkitt's lymphoma, this now includes some tumours that had long been suspected to be EBV associated, such as Hodgkin's disease, and some more unlikely candidates, such as gastric carcinomas and certain smooth muscle derived neoplasms. Molecular epidemiological studies have shown that for most of these entities the association with $\mathrm{EBV}$ is variable, depending on factors such as the geographical origin of the patient (for example, Burkitt's lymphoma) or histological subtype (for example, Hodgkin's disease). Moreover, a combination of molecular and morphological studies has shown that in some EBV associated tumours the virus is present only in a proportion of neoplastic cells (for example, $\mathrm{T}$ cell lymphomas), raising questions about the role of the virus in the pathogenesis of these tumours.

No human tumour entity is as consistently associated with EBV as non-keratinising nasopharyngeal carcinoma (NPC). Virtually all cases are EBV positive, regardless of geographical origin, and the virus is present in all tumour cells. Nevertheless, for no other of the established EBV associated tumours has the role of EBV been so controversially discussed. ${ }^{1}$ In particular, epidemiologists have questioned the relevance of EBV for the development of NPC, instead emphasising the importance of dietary carcinogens, such as salted fish products. Nevertheless, EBV has been classified as a group I carcinogen by the International Agency for Research on Cancer (IARC), among other reasons, because of its association with $\mathrm{NPC}^{1}$.
The purpose of this article is to review the evidence implicating EBV in the pathogenesis of NPC.

Role of epithelial versus $B$ cells in primary and persistent EBV infection: relevance for NPC pathogenesis

EBV is a ubiquitous human herpesvirus infecting over $90 \%$ of the adult population worldwide. Primary EBV infection usually occurs early in life and is asymptomatic. If primary EBV infection is delayed a clinical syndrome may result, infectious mononucleosis. ${ }^{2}$ In any case, primary infection is followed by life long virus persistence, which again is asymptomatic in most cases.

Our current knowledge of primary EBV infection is largely based on studies of patients with infectious mononucleosis, and rests on the (unconfirmed) assumption that the changes seen in infectious mononucleosis are representative also of asymptomatic primary infection. Infectious mononucleosis is a benign, self limiting lymphoproliferative disorder characterised morphologically by a proliferation of lymphoid blasts in the extrafollicular areas of tonsils. ${ }^{3}$ These consist partly of EBV infected B lymphoid blasts which, based on reverse transcription polymerase reaction (RT-PCR) studies, are characterised by a latency III pattern of viral gene expression; that is, EBV encoded RNA positive/EBV nuclear antigen 2 positive/latent membrane protein 1 positive $\left(\mathrm{EBER}^{+} / \mathrm{EBNA} 2^{+} / \mathrm{LMP}^{+}\right) .{ }^{4}$ However, analysis at the single cell level has revealed an unexpected degree of heterogeneity, with $\mathrm{EBER}^{+} / \mathrm{EBNA}^{-} / \mathrm{LMP}^{-}$cells, $\mathrm{EBER}^{+} /$ $\mathrm{EBNA}^{-} / \mathrm{LMP}^{+}{ }^{+}$cells, and $\mathrm{EBER}^{+} / \mathrm{EBNA}^{+} /$ $\mathrm{LMP}^{-}$cells being present in addition to $\mathrm{EBER}^{+} / \mathrm{EBNA}^{+} / \mathrm{LMP}{ }^{+}{ }$cells. ${ }^{3}$ In fact, cells conforming to the expected latency III pattern appear to be in the minority in infectious mononucleosis. ${ }^{3}$ The proliferation of EBV infected $B$ cells in turn elicits a cytotoxic $T$ cell reaction, which is directed against most of the viral latent proteins with the exception of EBNA1. ${ }^{56}$ This cytotoxic $\mathrm{T}$ lymphocyte (CTL) response allows the control of EBV infection and the transition into asymptomatic virus persistence.

The question as to which cellular compartments mediate primary and persistent EBV infection has been controversially discussed. Models developed in the 1980s have proposed a central role for oropharyngeal epithelial cells in both primary and persistent infection. ${ }^{7}$ These models were based largely on two observations. First, the detection of EBV in desquamated oropharyngeal epithelial cells in primary and persistent EBV infection had been 
reported. ${ }^{8}{ }^{9}$ Second, EBV replication had been demonstrated in epithelial cells of oral hairy leukoplakia, an AIDS associated lesion of the tongue. ${ }^{10}$ However, studies of infectious mononucleosis tonsils have consistently demonstrated the virus in B cells but not in epithelial cells. ${ }^{311}$ Importantly, two recent independent studies found no evidence of EBV infection in desquamated oropharyngeal epithelial cells, and thus did not confirm the earlier studies. ${ }^{12}{ }^{13}$ Moreover, although EBV replication is clearly detectable in the superficial epithelial cell layers of oral hairy leukoplakia, there is no evidence of latent persistent infection in this lesion. ${ }^{14} \mathrm{~A}$ recent PCR survey of tissues from the upper aerodigestive tract has also led to the conclusion that this site is not a major EBV reservoir. ${ }^{15}$ Thus, these and other studies have cast doubt on earlier models and, more recently, the role of $B$ cells as the main reservoir of virus persistence and, possibly, the main target of primary EBV infection has been emphasised. ${ }^{16}{ }^{17} \mathrm{Sev}-$ eral recent studies from Thorley-Lawson's group have established resting memory B cells as a major site of EBV persistence. ${ }^{18-20}$

This raises the question as to when EBV infection of epithelial cells occurs during the pathogenesis of NPC. EBV has not been detected in normal nasopharyngeal epithelial cells either adjacent to EBV positive NPC or in patients biopsied for suspected NPC. ${ }^{21-24}$ However, EBV infection has been demonstrated in in situ carcinomas of the nasopharynx, which are presumed precursor lesions of NPC. ${ }^{25} 26$ Taken together, these findings seem to suggest that EBV infection takes place before invasive growth begins, but probably does not represent the first step in the pathogenesis of NPC. This notion is also supported by in vitro studies, which have shown that stable EBV infection of epithelial cells may require an undifferentiated phenotype. ${ }^{27}$ Thus, one could speculate that epithelial cells might become susceptible to EBV infection as a result of exposure to environmental carcinogens-for example, in the form of dietary factors such as salted fish. ${ }^{1}$

Yet another unresolved issue is the mechanism by which EBV enters epithelial cells. The balance of evidence now suggests that the $\mathrm{C} 3 \mathrm{~d} / \mathrm{EBV}$ receptor $(\mathrm{CD} 21)$ that facilitates the infection of $\mathrm{B}$ cells is not expressed in human epithelial cells in vivo. ${ }^{28}{ }^{29}$ However, low degrees of CD21 expression in epithelial cells in vitro have been reported, and Fingeroth et al have described CD21 mediated infection of an epithelial cell line with EBV. ${ }^{30}{ }^{31}$ Imai et al have reported the infection of 18 of 21 human epithelial cell lines with EBV by co-cultivation with EBV producing $\mathrm{B}$ cells, suggesting that direct cell contact might allow EBV infection of CD21 negative cells, a mechanism first proposed by Bayliss and Wolf. ${ }^{32} 33$ The presence of EBV infected lymphocytes showing evidence of lytic infection in the nasopharyngeal mucosa suggests that this might also be a possible mechanism for EBV infection of epithelial cells in vivo. ${ }^{21}$

\section{EBV association of NPC histotypes}

Nasopharyngeal carcinomas occur worldwide with variable incidence. In Western countries the tumour is rare (annual incidence, $<0.5$ cases/100 000), whereas in some parts of South East Asia, North Africa, Greenland, and Alaska it is a common human cancer (annual incidence in Hong Kong 25/100 000 men; incidence figures from GLOBOCan database, IARC, Lyon, France, http://www.iarc.fr). The WHO classification of nasopharyngeal carcinomas distinguishes two major types, squamous cell carcinoma and non-keratinising carcinoma, the latter including undifferentiated carcinoma as a subtype. Non-keratinising carcinomas are commonly associated with a prominent lymphoid stroma consisting of lymphocytes, histiocytes, eosinophils, and other reactive cellular elements. These tumours are therefore also termed lymphoepithelial carcinomas or lymphoepitheliomas. By contrast, squamous cell carcinomas of the nasopharynx typically elicit a desmoplastic stroma reaction and therefore are commonly not accompanied by a lymphoid stroma. The proportions of the histological types appear to show some variability, but in all populations undifferentiated carcinomas account for most cases.

The association of non-keratinising nasopharyngeal carcinomas, particularly of the undifferentiated subtype, with EBV is well established. EBV has been detected in virtually all cases, irrespective of the geographic origin, and thus appears to be a rate limiting step in the pathogenesis of these tumours. By contrast, the question as to the possible association of squamous cell NPCs with EBV has been a matter of controversy going back to early seroepidemiological studies-raised EBV specific antibody titres have been reported in patients with all types of NPC or, alternatively, only in patients with non-keratinising NPC. ${ }^{34}{ }^{35}$ Similarly, studies attempting to detect viral nucleic acids and proteins in tumour samples have produced conflicting results. Klein et al have reported the detection of EBV DNA and of the EBNA complex in non-keratinising but not squamous cell NPCs. ${ }^{36}$ Using in situ hybridisation for the detection of EBV DNA and EBERs, we have obtained similar results. ${ }^{23} 37$ Moreover, using PCR, several groups have consistently detected viral DNA in nonkeratinising NPCs but only in a small proportion of squamous cell NPCs. ${ }^{23}{ }^{38}$ These latter findings are consistent with the occasional presence of EBV carrying lymphocytes in the stroma of squamous cell NPCs. By contrast, using Southern blot hybridisation, others have detected EBV DNA in DNA extracts from all squamous cell NPCs examined. ${ }^{39}$ Using in situ hybridisation, the same laboratory later demonstrated EBER expression in the neoplastic cells in all of 31 squamous cell NPCs. ${ }^{40}$ This apparent conflict has been resolved by the demonstration that squamous cell NPCs from a high incidence area (Hong Kong) are invariably EBV associated, whereas only approximately a third of the cases from a low incidence region (UK) are EBV positive, as assessed by EBER in situ hybridisation. ${ }^{41}$ Thus, squamous 
cell NPCs appear to show geographical variability with regard to their EBV association and, in this respect, are similar to Burkitt's lymphoma. These observations also suggest that, unlike non-keratinising NPCs, squamous cell NPCs represent a pathogenetically heterogeneous group of tumours. Recent studies have indicated that smoking and/or infection with human papillomaviruses (HPVs) might be involved in the pathogenesis of squamous cell NPCs. Vaughan et al have identified smoking as a risk factor for squamous cell but not for nonkeratinising NPCs, concluding that smoking accounts for two thirds of squamous cell NPCs. ${ }^{42}$ Using PCR, Hording et al have detected HPV DNA in some squamous cell NPCs that were EBV negative. ${ }^{43}$ However, Rassekh et al have reported the detection of EBV and HPV by PCR in $88 \%$ and $53 \%$ of nasopharyngeal carcinomas, respectively. ${ }^{44}$ In that study, all HPV positive cases were also EBV positive. Unexpectedly, there was a tendency for HPV positive cases to show an undifferentiated histology and for the HPV negative cases to be squamous cell NPCs. Clearly, further studies are required to resolve this issue. In particular, it will be necessary to study EBV and HPV infection in NPCs at the single cell level.

\section{EBV infection, viral latent gene expression, and tumour cell phenotype in NPCs}

In non-keratinising NPCs, the virus is detectable in almost all cancer cells, where it is present as a monoclonal episome (fig 1A). ${ }^{26}{ }^{45}$ More recently, monoclonal viral genomes have also been detected in in situ NPCs. ${ }^{25}$ This suggests that EBV infection takes place before the expansion of the malignant cell clone, and thus places the virus into the appropriate time frame to be involved in the pathogenesis of non-keratinising NPC. Similarly, monoclonal viral episomes have been detected in all EBV associated squamous cell NPCs investigated. ${ }^{40}$

Expression of the viral genome in nonkeratinising NPC has been studied extensively. In general, these studies have revealed a type II EBV latent infection. Expression of the EBERs has been detected by in situ hybridisation. ${ }^{46}$ Western blot and immunohistochemistry studies have shown the presence of EBNA1 in the tumour cells. ${ }^{47} 48$ At present it is uncertain if, apart from its known role in the maintenance of the viral episome, ${ }^{49}$ EBNA1 expression contributes to the pathogenesis of NPCs. Latent transcripts running through the BamHI A region of the viral genome are also regularly detected in NPCs. ${ }^{50}{ }^{51}$ The importance of this observation remains uncertain.

LMP1 expression is detectable at the protein level in up to $65 \%$ of cases using western blotting or immunohistochemistry, and at the transcriptional level in virtually all cases using sensitive PCR assays. ${ }^{47} 5253$ In view of the known transforming ability of this protein, ${ }^{54} 55$ this observation adds support to the notion that $\mathrm{EBV}$ is involved in the pathogenesis of NPC. Functionally, LMP1 is similar, but not identical to CD40, a member of the tumour necrosis factor (TNF) receptor family. ${ }^{56}{ }^{57} \mathrm{LMP} 1 \mathrm{~mol}-$ ecules aggregate in the cell membrane and, through two C-terminal activating regions, interact with TNF receptor associated factors (TRAFs) and TNF receptor associated death domain protein (TRADD). ${ }^{56-58}$ In vitro, LMP1 expression in epithelial cells can induce or upregulate the expression of intercellular adhesion molecule 1 (ICAM-1), CD40, and cytokines such as interleukin 6 (IL-6) and IL-8. ${ }^{55}$ 59 Moreover, LMP1 can induce the expression of the CD70 antigen, a member of the TNF family, in epithelial cells in vitro. ${ }^{60} 61$ This observation is relevant because most nonkeratinising NPCs are CD70 positive, although CD70 expression in NPCs does not appear to correlate with the detection of the LMP1 protein. ${ }^{62}$ In addition, members of the $\mathrm{B} 7$ family (CD80/86) have been detected in the neoplastic cells of some non-keratinising NPCs and, importantly, this feature appears to be restricted to cases showing LMP1 expression as detected by immunohistochemistry. ${ }^{62}$ Furthermore, LMP1 can induce a matrix metalloproteinase, MMP-9, through C-terminal activating regions 1 and 2 (CTAR- 1 and CTAR2 ), an effect blocked by overexpression of $\mathrm{I} \kappa \mathrm{B} .{ }^{63}$ If realised in vivo, this might contribute to the invasive growth of NPC. Nevertheless, the role of LMP1 in the pathogenesis of nonkeratinising NPC remains to be defined. In particular, it has been shown that LMP1, again similar to CD40, can have a growth inhibitory function in certain epithelial cells. ${ }^{57}$ NPC tumours with detectable LMP1 protein synthesis appear to present at a more advanced stage than their LMP1 negative counterparts, yet unexpectedly LMP1 expression appears to be a favourable prognostic marker. ${ }^{64}$ Moreover, transfection of LMP1 into EBV negative gastric carcinoma cells resulted in reduced growth rate, reduced colony forming efficiency, reduced tumorigenicity, lower cytological grade, and increased sensitivity for apoptosis. ${ }^{65}$

The expression of LMP2A and LMP2B mRNA in non-keratinising NPCs is readily detectable by RT-PCR. ${ }^{53}$ However, to date, detection of the protein has not been reported. ${ }^{66}$ Using immunohistochemistry, we have been unable to detect LMP2A expression in a large series of primary undifferentiated NPCs (G Niedobitek et al, 1998, unpublished data). However, a single case of an EBV positive, non-keratinising metastatic carcinoma in a cervical lymph node of presumed (but unconfirmed) nasopharyngeal origin showed strong LMP2A expression (fig 1B), demonstrating at least that expression of this protein in carcinoma cells is possible. However, in contrast to Hodgkin's disease, where LMP2A is frequently detectable by immunostaining, ${ }^{66}$ expression in non-keratinising NPCs appears to occur only rarely, or at a very low level. Because LMP2 is a possible target for immunotherapeutic approaches to the treatment of NPC, ${ }^{67}$ this issue requires clarification. The function of LMP2 in NPC is uncertain. It has been suggested that in B cells, LMP2A might inhibit entry into the lytic viral cycle in response to antigen triggering. ${ }^{68}$ More recently, 


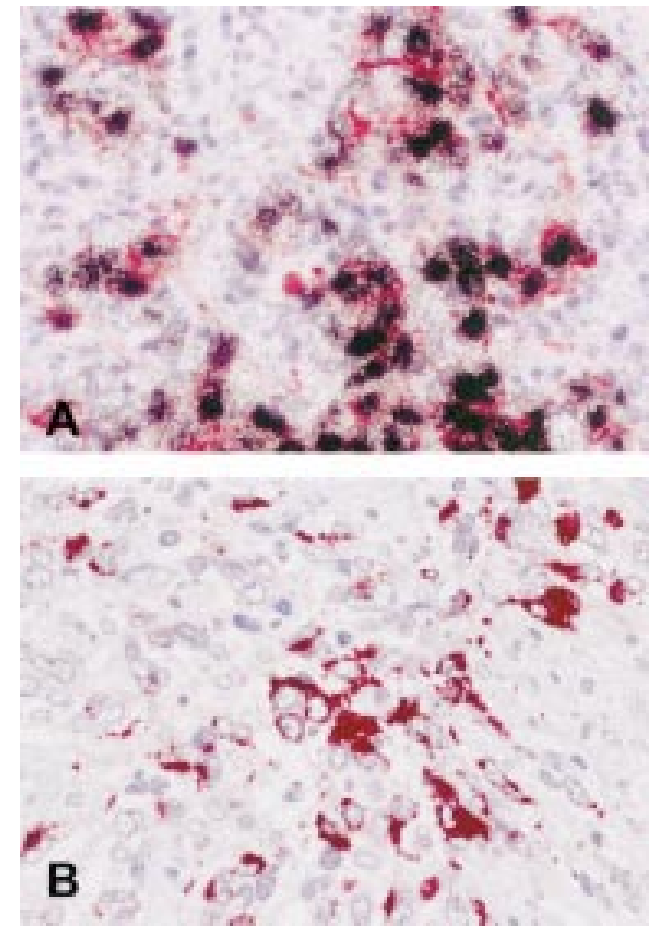

Figure 1 (A) Double labelling in situ hybridisation and immunohistochemistry reveals expression of the Epstein-Barr virus (EBV) encoded RNAs (EBERs) (black grains) in virtually all cytokeratin positive (red labelling) tumour cells of an undifferentiated nasopharyngeal carcinoma. (B) Detection of latent membrane protein $2 A$ (LMP2A) by immunohistochemistry in an Epstein-Barr virus positive undifferentiated carcinoma (see text).

LMP2A has also been shown to substitute for the pre B cell receptor in B cell development. ${ }^{69}$ In epithelial cells, the phosphorylation of LMP2A is triggered by interaction with extracellular matrix proteins, ${ }^{70}$ suggesting that LMP2A interacts with adhesion initiated signalling pathways.

EBV associated squamous cell NPC shows a similar pattern of viral latent gene transcription to non-keratinising NPC. Transcripts derived from the genes encoding EBNA1, LMP1, and LMP2, as well as from the BamHI A fragment of the viral genome, have been detected by

Cytokines/Chemokines

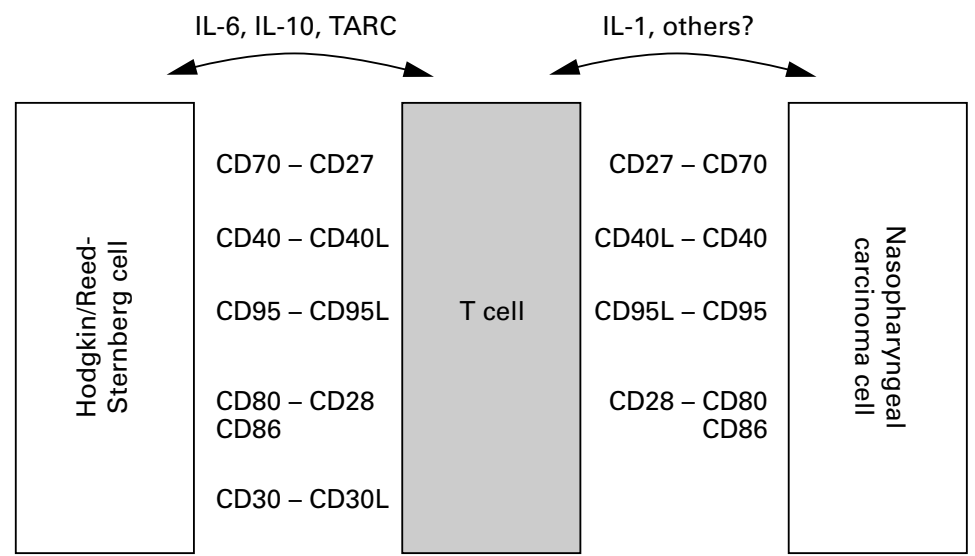

Figure 2 Possible interactions between tumour cells and tumour infiltrating lymphocytes in Hodgkin's disease (left) and undifferentiated nasopharyngeal carcinoma (right, modified and extended from Gruss and colleagues ${ }^{77}$ ). IL, interleukin; TARC, thymus and activation regulated chemokine.
RT-PCR. ${ }^{40}$ However, LMP1 expression is only rarely detectable using immunohistochemistry. ${ }^{41}$ The detection of LMP1 by immunohistochemistry in in situ NPCs has also been reported, and this has been taken as further evidence in support of an aetiological role for EBV in the pathogenesis of NPCs. ${ }^{40}$ However, this observation has not been reproducible in our hands (G Niedobitek et al, 1996, unpublished data) and thus the issue of EBV latent gene expression in in situ NPCs requires further investigation.

\section{Tumour cell phenotype and lymphoid stroma in nasopharyngeal carcinoma: comparison with Hodgkin's disease}

A characteristic feature of non-keratinising NPC is the presence of numerous lymphoid and other inflammatory cells, which are intimately admixed with the tumour cells, forming the so called lymphoid stroma. This has been variably regarded as pre-existing lymphoid tissue or as the result of a host immune response directed against the tumour. NPC cells express viral antigens that might serve as targets for EBV specific CTLs (see above). In vitro, these cells display a normal antigen processing function and are efficiently recognised by human major histocompatibility complex (HLA) class I restricted, virus specific CTLs. ${ }^{71}$ Moreover, NPCs express CD95 and are susceptible to Fas mediated lysis, although this might be inhibited by CD40 signalling. ${ }^{72}$ Phenotypic studies have shown that immune regulatory receptor ligand pairs are expressed in NPCs, which should allow the epithelial tumour cells to interact with tumour infiltrating lymphocytes. Thus, the expression of CD40, CD70, and CD80/86 has been demonstrated in NPC tumour cells, and the corresponding receptors/ligands CD40L, CD27, and CD28 are detectable in admixed lymphocytes. ${ }^{62}$ Interestingly, expression of CD40, CD70, and CD80 in nonimmunogenic tumour cells can induce strong antitumour CTL responses in animal experiments. ${ }^{73}$ Thus, these observations raise the question as to why NPC tumours in vivo can apparently grow in the face of an otherwise intact EBV specific immunity.

Hodgkin's disease, another EBV associated tumour, is also characterised by a dense reactive infiltrate consisting of lymphocytes, eosinophils, and other cells, which vastly outnumber the neoplastic Hodgkin and ReedSternberg (HRS) cells. Albeit of different cell lineage (epithelial versus lymphoid), both neoplasms share several other features that warrant closer examination. Like NPC cells, EBV positive HRS cells display a latency II pattern of EBV gene expression, with detectable expression of LMP1 and LMP2A. ${ }^{6674}$ HRS cells are also capable of presenting EBV encoded antigens in the context of major histocompatibility complex (MHC) class I and are susceptible to lysis by EBV specific CTLs in vitro. ${ }^{75} 76$ Moreover, HRS cells frequently express CD40, CD70, CD80, and CD95, thus showing further parallels with NPC cells. The T cells surrounding the HRS cells have been shown to 
be activated CD4 positive cells with a $\mathrm{T}$ helper type 2 (Th2) phenotype. ${ }^{77}$ Recent studies have suggested that HRS cells, through the production of an array of cytokines and chemokines, might contribute to the accumulation of lymphocytes in affected tissues. HRS cells express the thymus and activation regulated chemokine (TARC), which selectively recruits CCR4 positive Th2 cells. ${ }^{79}$ Furthermore, certain cytokines expressed by HRS cells might help to modulate the local immune response, thus dampening down any EBV specific immunity. ${ }^{80}$ This effect might be partially mediated by IL-10, which is strongly expressed in EBV positive HRS cells. ${ }^{81}{ }^{82}$ Moreover, IL-6 expression has been observed preferentially in EBV positive HRS cells. ${ }^{83}$ Thus, although HRS cells are effective antigen presenting cells susceptible to CTL lysis, they seem to be able actively to modulate their microenvironment, resulting in an ineffective immune response. Figure 2 summarises the possible interactions between tumour cells and infiltrating lymphocytes in Hodgkin's disease and NPC.

In comparison with Hodgkin's disease, the nature of the interaction between tumour cells and tumour infiltrating lymphocytes in nonkeratinising NPC is poorly understood. Like HRS cells, NPC cells appear to be able to secrete cytokines. Studies of NPC cell lines have revealed variable expression of IL- $1 \alpha$, IL- $1 \beta$, TNF- $\alpha$, and IL- 8 in some lines, but a consistent pattern has not emerged yet. ${ }^{84}{ }^{85}$ To date, there is only very limited information available regarding the cytokine expression patterns in non-keratinising NPCs in vivo. Huang et al have demonstrated IL-1 expression in NPC tumour cells, with several other cytokines expressed in the lymphoid stroma. ${ }^{86}$ IL-10 expression has been reported and has been suggested to be a marker of poor prognosis in NPCs. ${ }^{87} 88$ However, studying a large series of NPCs by in situ hybridisation, we could not confirm this observation (G Niedobitek et al, 2000, unpublished data). IL-6 and IL-8 expression was detectable only in exceptional cases and then only in a small fraction of the tumour cells, raising questions as to the importance of this finding (G Niedobitek et al, 2000, unpublished data). TARC expression was undetectable in NPCs (G Niedobitek et al, 2000, unpublished data). Significantly raised serum concentrations of transforming growth factor $\beta$ (TGF- $\beta$ ) have been reported in patients with NPC but the cellular source of this cytokine is presently uncertain. ${ }^{89}$

\section{Conclusions}

The association of NPC with EBV has been firmly established since $1973 .^{90}$ However, the evidence indicating a role for the virus in the pathogenesis of NPC is still largely circumstantial and controversial. ${ }^{1}$ Recent studies have found that squamous cell NPCs and nonkeratinising NPCs vary with regard to their EBV association. Squamous cell NPCs may be EBV negative, and other factors such as smoking or HPV infection might be involved in the pathogenesis. Thus, these tumours appear to be pathogenetically heterogeneous. By con- trast, non-keratinising NPCs are almost always EBV positive, suggesting that the virus is a rate limiting step for these tumours. It seems reasonable, therefore, to assume that EBV somehow contributes to the pathogenesis of non-keratinising NPCs. Yet, at the same time there is a growing body of evidence to suggest that EBV infection might not be the first step in the development of these tumours. It will be important to define the exact timing of EBV infection of nasopharyngeal epithelial cells and to identify the factors that precede and probably pave the way for EBV infection.

EBV associated NPC has been proposed as a promising target for virus specific immunotherapy. However, it appears unlikely at present that the approach used successfully for the prevention and treatment of post-transplant lymphoproliferative disorders can be easily adopted for NPC. ${ }^{91}$ Like HRS cells, NPC tumour cells are capable of presenting viral antigen and are susceptible to MHC class I restricted CTL lysis in vitro. ${ }^{71}{ }^{75}$ Nevertheless, these tumours grow in vivo although patients usually do not display any gross deficiencies in their EBV specific immunity. Studies of Hodgkin's disease have shown that the neoplastic cells might modulate the local immune response through the elaboration of cytokines and chemokines, and that this ability might be enhanced by EBV infection. Currently, it is uncertain whether this is also true for NPC. Defining the function of the lymphoid stroma typically seen in NPCs will be pivotal for understanding the pathogenesis of NPC and is also required for devising promising immunotherapeutic strategies.

1 International Agency for Research on Cancer. Epstein-Barr virus and Kaposi's sarcoma herpesvirus/human herpesvirus 8 . to humans, Vol. 70. Lyon, France: WHO, 1997.

2 Evans AS. Clinical syndromes associated with EB virus infection. Ann Intern Med 1972;18:77-93.

3 Niedobitek G, Agathanggelou A, Herbst H, et al. EpsteinBarr virus (EBV) infection in infectious mononucleosis: virus latency, replication and phenotype of EBV-infected cells. F Pathol 1997;182:151-9.

4 Tierney RJ, Steven N, Young LS, et al. Epstein-Barr virus latency in blood mononuclear cells: analysis of viral gene state. F Virol 1994;68:7374-85.

5 Tosato G, Magrath I, Koski I, et al. Activation of suppressor $\mathrm{T}$ cells during Epstein-Barr-virus-induced infectious $\mathrm{T}$ cells during Epstein-Barr-virus-induced

6 Levitskaya J, Coram M, Levitsky V, et al. Inhibition of antigen processing by the internal repeat region of the EpsteinBarr virus nuclear antigen-1. Nature 1995;375:685-8

7 Allday MJ, Crawford DH. Role of epithelium in EBV persistence and pathogenesis of B-cell tumours. Lancet 1988;i:855-7.

8 Lemon SM, Hutt LM, Shaw JE, et al. Replication of EBV in epithelial cells during infectious mononucleosis. Nature 1977;70:268-70.

9 Sixbey JW, Nedrud JG, Raab-Traub N, et al. Epstein-Barr virus replication in oropharyngeal epithelial cells. $N$ Engl $\mathcal{F}$ Med 1984;310:1225-30.

10 Greenspan JS, Greenspan D, Lennette ET, et al. Replication of Epstein-Barr virus within the epithelial cells of oral hairy eukoplakia, an AIDS-associated lesion. $N$ Engl f Med 1985;313:1564-71.

11 Niedobitek G, Hamilton-Dutoit S, Herbst H, et al. Identification of Epstein-Barr virus-infected cells in tonsils of acute infectious mononucleosis by in situ hybridization. Hum Pathol 1989;20:796-9.

12 Karajannis MA, Hummel M, Anagnostopoulos I, et al. Strict lymphotropism of Epstein-Barr virus during acute
infectious mononucleosis in nonimmunocompromised individuals. Blood 1997;89:2856-62.

13 Niedobitek G, Agathanggelou A, Steven N, et al. EpsteinBarr virus (EBV) in infectious mononucleosis: detection of the virus in tonsillar B lymphocytes but not in desquathe virus in tonsillar B lymphocytes but not in desqua-
mated oropharyngeal epithelial cells. F Clin Pathol: Mol Pathol 2000;53:37-42. 
14 Niedobitek G, Young LS, Lau R, et al. Epstein-Barr virus infection in oral hairy leukoplakia: virus replication in the 1991;72:3035-46.

15 Liavaag PG, Cheung RK, Kerrebijn JD, et al. The physiologic reservoir of Epstein-Barr virus does not map to upper aerodigestive tissues. Laryngoscope 1998;108:42-6.

16 Niedobitek G, Young LS. Epstein-Barr virus persistence and virus-associated tumours. Lancet 1994;343:333-5.

17 Thorley-Lawson DA, Miyashita EM, Khan G. Epstein-Bar virus and the B cell: that's all it takes. Trends Microbiol 1996;4:204-8.

18 Babcock GJ, Decker LL, Volk M, et al. EBV persistence in memory B cells in vivo. Immunity 1998;9:395-404.

19 Miyashita EM, Yang B, Lam KMC, et al. A novel form of Epstein-Barr virus latency in normal B cells in vivo. Cell 1995;80:593-601.

20 Khan G, Miyashita EM, Yang B, et al. Is EBV persistence in vivo a model for B cell homeostasis? Immunity 1996;5:1739.

21 Tao Q, Srivastava G, Chan ACL, et al. Evidence for lytic infection by Epstein-Barr virus in mucosal lymphocyte instead of nasopharyngeal epithelial cells in normal individuals. F Med Virol 1995;45:71-7.

22 Sam CK, Brooks LA, Niedobitek G, et al. Analysis of Epstein-Barr virus infection in nasopharyngeal biopsies from a group at high risk of nasopharyngeal carcinoma. Int f Cancer 1993;53:957-62.

23 Niedobitek G, Hansmann ML, Herbst H, et al. EpsteinBarr virus and carcinomas: undifferentiated carcinomas but not squamous cell carcinomas of the nasopharynx are regularly associated with the virus. F Pathol 1991;165:1724 .

24 Weiss LM, Movahed LA, Butler AE, et al. Analysis of lymphoepithelioma and lymphoepithelioma-like carcinomas for Epstein-Barr virus by in situ hybridization. $A m \mathcal{F}$ mas for Epstein-Barr virus by

25 Pathmanathan R, Prasad U, Sadler R, et al. Clonal proliferations of cells infected with Epstein-Barr virus in preinvasive lesions related to nasopharyngeal carcinoma. $N \mathrm{Engl} F \mathrm{Med}$ 1995;333:693-8.

26 Niedobitek G, Agathanggelou A, Nicholls JM. Epstein-Barr virus infection and the pathogenesis of nasopharyngeal carcinoma: viral gene expression, tumour cell phenotype, and the role of the lymphoid stroma. Semin Cancer Biol 1996;7:165-74.

27 Knox PG, Li Q-X, Rickinson AB, et al. In vitro production of stable Epstein-Barr virus-positive epithelial cell clones which resemble the virus:cell interaction observed in nasopharyngeal carcinoma. Virology 1996;215:40-50.

28 Young LS, Dawson CW, Brown KW, et al. Identification of a human epithelial cell surface protein sharing an epitope human epithelial cell surface protein sharing an epitope with the C3d/Epstein-Barr virus receptor
lymphocytes. Int $\mathcal{F}$ Cancer 1989;43:786-94.

29 Niedobitek G, Herbst H, Stein H. Epstein-Barr virus/ complement receptor and epithelial cells. Lancet 1989;II 110 .

30 Fingeroth JD, Diamond ME, Sage DR, et al. CD21dependent infection of an epithelial cell line, 293, by Epstein-Barr virus. F Virol 1999;73:2115-25.

31 Birkenbach $\mathrm{M}$, Tong X, Bradbury LE, et al. Characterization of an Epstein-Barr virus receptor on human epithelial cells. F Exp Med 1992;176:1405-14.

32 Imai S, Nishikawa J, Takada K. Cell-to-cell contact as an efficient mode of Epstein-Barr virus infection of diverse human epithelial cells. F Virol 1998;72:4371-8.

33 Bayliss GJ, Wolf $\mathrm{H}$. Epstein-Barr virus-induced cell fusion. Nature 1980;287:164-5.

34 Henle W, Henle G, Ho H-C, et al. Antibodies to Epstein-Barr virus in nasopharyngeal carcinoma, other head and neck neoplasms, and control groups. $\mathcal{F}$ Natl Cancer Inst 1970;44:225-31.

35 Micheau C. What's new in histological classification and recognition of naso-pharyngeal carcinoma (N.P.C.). Pathol Res Pract 1986;181:249-53.

36 Klein G, Giovanella BC, Lindahl T, et al. Direct evidence for the presence of Epstein-Barr virus DNA and nuclear antigen in malignant epithelial cells from patients with poorly differentiated carcinoma of the nasopharynx. Proc Nat Acad Sci U S A 1974;71:4737-41.

37 Niedobitek G, Agathanggelou A, Barber P, et al. p53 overexpression and Epstein-Barr virus infection in undifferentiated and squamous cell nasopharyngeal carcinomas. $\mathcal{F}$ Pathol 1993;170:457-61.

38 Hording U, Nielsen HW, Albeck H, et al. Nasopharyngeal carcinoma-histopathological types and association with $137-9$.

39 Raab-Traub N, Flynn K, Pearson G, et al. The differentiated form of nasopharyngeal carcinoma contains Epstein Barr virus DNA. Int 7 Cancer 1987;39:25-9.

40 Pathmanathan R, Prasad U, Chandrika G, et al. Undifferentiated, non-keratinising, and squamous cell carcinoma of the nasopharynx. Variants of Epstein-Barr virus-infected neoplasia. Am f Pathol 1995;146:1355-67.

41 Nicholls JM, Agathanggelou A, Fung K, et al. The association of squamous cell carcinomas of the nasopharynx with Epstein-Barr virus shows geographic variation reminiscent of Burkitt's lymphoma. f Pathol 1997;183:1648 .

42 Vaughan TL, Shapiro JA, Burt RD, et al. Nasopharyngeal cancer in a low-risk population-defining risk factors by
histological type. Cancer Epidemiol Biomarkers Prev 1996;5: 587-93.
43 Hording U, Winther Nielsen H, Daugaard S, et al. Human papillomavirus types 11 and 16 detected in nasopharyngeal carcinomas by the polymerase chain reaction. Laryngoscope 1994;104:99-102.

44 Rassekh CH, Rady PL, Arany I, et al. Combined Epstein-Barr virus and human papillomavirus infection in nasopharyngeal carcinoma. Laryngoscope 1998;108:362-7.

45 Raab-Traub N, Flynn K. The structure of the termini of the Epstein-Barr virus as a marker of clonal cellular proliferation. Cell 1986;47:883-9.

46 Wu T-C, Mann RB, Epstein JI, et al. Abundant expression of EBER1 small nuclear RNA in nasopharyngeal carcinoma. A morphologically distinct target for detection of EpsteinBarr virus in formalin-fixed paraffin-embedded carcinoma specimens. Am ₹ Pathol 1991;138:1461-9.

47 Young L, Dawson C, Clark D, et al. Epstein-Barr virus gene expression in nasopharyngeal carcinoma. $f$ Gen Virol 1988; 69:1051-65.

48 Murray PG, Niedobitek G, Kremmer E, et al. In situ detection of the Epstein-Barr virus-encoded nuclear antigen 1 in oral hairy leukoplakia

49 Yates J, Waren N, Reisman D, et al. A cis-acting element from the Epstein-Barr virus genome that permits stable replication of recombinant plasmids in latently infected cells. Proc Natl Acad Sci U S A 1984;81:3806-10.

50 Brooks LA, Lear AL, Young LS, et al. Transcripts from the Epstein-Barr virus BamHI A fragment are detectable in all three forms of virus latency. $\mathcal{F}$ Virol 1993;67:3182-90.

51 Gilligan KJ, Rajadurai P, Lin J-C, et al. Expression of the Epstein-Barr virus BamHI A fragment in nasopharyngeal carcinoma: evidence for a viral protein expressed in vivo. $\mathcal{F}$ Virol 1991;65:6252-9.

52 Niedobitek G, Young LS, Sam CK, et al. Expression of Epstein-Barr virus genes and of lymphocyte activation molecules in undifferentiated nasopharyngeal carcinomas. Am ₹ Pathol 1992;140:879-87.

53 Brooks L, Yao QY, Rickinson AB, et al. Epstein-Barr virus atent gene transcription in nasopharyngeal carcinoma cells: coexpression of EBNA1, LMP1, and LMP2 transcripts. F Virol 1992;66:2689-97.

54 Wang D, Liebowitz D, Kieff E. An EBV membrane protein expressed in immortalized lymphocytes transforms established rodent cells. Cell 1985;43:831-40.

55 Dawson CW, Rickinson AB, Young LS. Epstein-Barr virus latent membrane protein inhibits human epithelial cell differentiation. Nature 1990;344:777-80.

56 Floettmann JE, Eliopoulos AG, Jones M, et al. Epstein-Barr virus latent membrane protein-1 (LMP1) signalling is distinct from CD40 and involves physical cooperation of its two C-terminus functional regions. Oncogene 1998;17: 2383-92.

57 Eliopoulos A, Dawson CW, Mosialos G, et al. CD40induced growth inhibition in epithelial cells is mimicked by Epstein-Barr virus-encoded LMP1: involvement of TRAF3 as a common mediator. Oncogene 1996;13:224354.

58 Ardila-Osorio H, Clausse B, Mishal Z, et al. Evidence of LMP1-TRAF3 interactions in glycosphingolipid-rich complexes of lymphoblastoid and nasopharyngeal carcinoma cells. Int $\mathcal{F}$ Cancer 1999;81:645-9.

59 Eliopoulos AG, Stack M, Dawson CW, et al. Epstein-Barr virus-encoded LMP1 and CD40 mediate IL-6 production in epithelial cells via an NF- $\mathrm{BB}$ pathway involving TNF receptor-associated factors. Oncogene 1997;14:2899916.

60 Niedobitek G, Fahraeus R, Herbst H, et al. The EpsteinBarr virus encoded membrane protein (LMP) induces phenotypic changes in epithelial cells. Virchows Arch B Cell Pathol 1992;62:55-9.

61 Hintzen RO, Lens SMA, Koopman G, et al. CD70 represents the human ligand for CD27. Int Immunol 1994; 6:477-80.

62 Agathanggelou A, Niedobitek G, Chen R, et al. Expression of immune regulatory molecules in Epstein-Barr virusassociated nasopharyngeal carcinomas with prominent lymphoid stroma. Evidence for a functional interaction between epithelial tumor cells and infiltrating lymphoid cells. Am f Pathol 1995;147:1152-60.

63 Takeshita H, Yoshizaki T, Miller WE, et al. Matrix metalloproteinase 9 expression is induced by Epstein-Barr virus and 2. F Virol 1999;73:5548-55.

$64 \mathrm{Hu}$ L-F, Chen F, Zhen Q-F, et al. Differences in the growth pattern and clinical course of EBV-LMP1 expressing and non-expressing nasopharyngeal carcinomas. Eur 7 Cancer 1995;31A:658-60.

65 Sheu LF, Chen A, Wei YH, et al. Epstein-Barr virus modulates the malignant potential of gastric carcinoma cells involving apoptosis. Am $\mathcal{F}$ Pathol 1998;152:63-74.

66 Niedobitek G, Kremmer E, Herbst H, et al. Immunohistochemical detection of the Epstein-Barr virus-encoded latent membrane protein 2A (LMP2A) in Hodgkin's disease and infectious mononucleosis. Blood 1997;90: 1664-72.

67 Ambinder RF, Robertson KD, Moore SM, et al. EpsteinBarr virus as a therapeutic target in Hodgkin's disease and nasopharyngeal carcinoma. Semin Cancer Biol 1996;7:21726.

68 Longnecker R, Miller CL. Regulation of Epstein-Barr virus latency by latent membrane protein 2. Trends Microbiol 1996;4:38-42. 
69 Caldwell RG, Wilson JB, Anderson SJ, et al. Epstein-Barr virus LMP2A drives B cell development and survival in the absence of normal $\mathrm{B}$ cell receptor signals. Immunity 1998:9:405-11.

70 Scholle F, Longnecker R, Raab-Traub N. Epithelial cell adhesion to extracellular matrix proteins induces tyrosine phosphorylation of the Epstein-Barr virus latent membrane protein 2: a role for C-terminal Src kinase. F Virol 1999;73: $4767-75$.

71 Khanna R, Busson P, Burrows SR, et al. Molecular characterization of antigen-processing function in nasopharyngeal carcinoma: evidence for efficient presentation of EpsteinBarr virus cytotoxic T-cell epitopes by NPC cells. Cancer Res 1998;58:310-14.

72 Sbih-Lammali F, Clausse B, Ardila-Osorio H, et al. Control of apoptosis in Epstein-Barr virus-positive nasopharyngeal carcinoma cells: opposite effects of CD95 and CD40 stimulation. Cancer Res 1999;59:924-30.

73 Nieland JD, Graus YF, Dortmans YE, et al. CD40 and CD70 co-stimulate a potent in vivo antitumor $T$ cell CD70 co-stimulate a potent in vivo

74 Herbst H, Dallenbach F, Hummel M, et al. Epstein-Barr virus latent membrane protein expression in Hodgkin and Reed-Sternberg cells. Proc Natl Acad Sci U S A 1991;88 4766-70.

75 Lee SP, Constandinou CM, Thomas WA, et al. Antigen presenting phenotype of Hodgkin Reed-Sternberg cells: analysis of the HLA class I processing pathway and effects of interleukin-10 on Epstein-Barr virus-specific cytotoxic T-cell recognition. Blood 1998;92:1020-30.

76 Sing AP, Ambinder RF, Hong DJ, et al. Isolation of EpsteinBarr virus (EBV)-specific cytotoxic $\mathrm{T}$ lymphocytes that lyse Reed-Sternberg cells: implications for immunemediated therapy of EBV+ Hodgkin's disease. Blood 1997; 89:1978-86.

77 Gruss H-J, Pinto A, Duyster J, et al. Hodgkin's disease: a tumor with disturbed immunologic pathways. Immunol today 1997;18:156-63.

78 van den Berg A, Visser L, Poppema S. High expression of the CC chemokine TARC in Reed-Sternberg cells. Am $\mathcal{F}$ Pathol 1999;154:1685-91.

79 Imai T, Nagira M, Takagi S, et al. Selective recruitment of CCR4-bearing Th2 cells toward antigen-presenting cells by the CC chemokines thymus and activation-regulated chemokine and macrophage-derived chemokine. Int Immunol 1999;11:81-8.
80 Frisan T, Sjoberg J, Dolcetti R, et al. Local suppression of Epstein-Barr virus (EBV)-specific cytotoxicity in biopsies of EBV-positive Hodgkin's disease. Blood 1995;86:1493501 .

81 Herbst H, Foss H-D, Samol J, et al. Frequent expression of interleukin-10 by Epstein-Barr virus-harboring tumor cells of Hodgkin's disease. Blood 1996;87:2918-29.

82 Bejarano MT, Masucci MG. Interleukin-10 abrogates the inhibition of Epstein-Barr virus-induced B-cell transformation by memory T-cell responses. Blood 1998;92:4256-62.

83 Herbst H, Samol J, Foss HD, et al. Modulation of interleukin-6 expression in Hodgkin and Reed-Sternberg cells by Epstein-Barr virus. F Pathol 1997;182:299-306.

84 Busson P, Braham K, Ganem G, et al. EBV containing epithelial cells from nasopharyngeal carcinoma produce IL-1 alpha. Proc Natl Acad Sci U S A 1987;84:6262-6.

85 Mahe Y, Hirose K, Clausse B, et al. Heterogeneity among human nasopharyngeal carcinoma cell lines for inflammatory cytokines mRNA expression levels. Biochem Biophys Res Commun 1992;187:121-6.

86 Huang YT, Sheen TS, Chen CL, et al. Profile of cytokine expression in nasopharyngeal carcinomas: a distinct expression of interleukin 1 in tumor and CD4+ $\mathrm{T}$ cells. Cancer Res 1999;59:1599-605.

87 Yao M, Ohshima J, Kume T, et al. Interleukin-10 expression and cytotoxic T-cell response in Epstein-Barr-virusassociated nasopharyngeal carcinoma. Int f Cancer 1997; $72: 398-402$

88 Fujieda S, Lee K, Sunaga H, et al. Staining of interleukin-10 predicts clinical outcome in patients with nasopharyngeal carcinoma. Cancer 1999;85:1439-45.

$89 \mathrm{Xu} \mathrm{J}$, Menezes J, Prasad U, et al. Elevated serum levels of transforming growth factor beta 1 in Epstein-Barr virus-associated nasopharyngeal carcinoma patients. Int $\mathcal{f}$ Cancer 1999;84:396-9.

90 Wolf $\mathrm{H}$, zur Hausen $\mathrm{H}$, Becker V. EB viral genomes in epithelial nasopharyngeal carcinoma cells. Nature 1973;244: $245-7$.

91 Rooney CM, Smith CA, Ng CYC, et al. Infusion of cytotoxic $\mathrm{T}$ cells for the prevention and treatment of Epstein-Barr virus-induced lymphoma in allogeneic transplant recipients. Blood 1998;92:1549-55. 